\title{
ENSINO DE GEOGRAFIA PARA DEFICIENTES VISUAIS: UMA PREPOSIÇÃO NA PERSPECTIVA DAS TECNOLOGIAS DE INFORMAÇÃO
}

Jaqueline Machado Vieira

Universidade Estadual Paulista - UNESP, curso de Geografia, Presidente Prudente, SP. E-mail: jakquet@hotmail.com. Bolsista do CPIDES - Agência Financiadora: Proex

\section{RESUMO}

O artigo visa discutir a utilização das Tecnologias de Informação e Comunicação (TIC) que auxiliam o educando com Deficiência Visual (DV) em seus estudos. Uma delas, a audiodescrição. As metodologias utilizadas foram atividades teóricas e práticas com um educando DV, como vídeos de audiodescrição e leituras tátil do alfabeto Braile. Foram ministradas leituras de textos sobre temas variados e que abarcaram a interpretação de conteúdos e problemáticas que possibilitaram ao estudante possuir uma postura crítica por meio de conhecimentos relacionados, principalmente, ao ensino-aprendizagem de Geografia. A pesquisa está sendo realizada no Centro de Promoção para Inclusão Digital Escolar e Social (CPIDES), na sala de recursos multifuncionais. 0 CPIDES foi fundado no dia 8 de abril de 2010 e se encontra localizado na Faculdade de Ciências e Tecnologia (FCT), da Universidade Estadual Paulista (UNESP) "Júlio de Filho Mesquita", campus de Presidente Prudente.

Palavras chave: Audiodescrição, Sala Multifuncional, CPIDES, TIC.

\section{GEOGRAPHY OF EDUCATION FOR VISUALLY IMPAIRED: ONE PROPOSITION IN THE PERSPECTIVE OF THE INFORMATION TECHNOLOGY}

\begin{abstract}
The article aims to discuss the use of Information and Communication Technologies (TICS) that assist the student with Vision Impaired (DV) in their studies. One of these is the audio-description. The methodologies used were theoretical and practical activities with a DV educating, as videos of audio-description and tactile reading Braille alphabet. Were taught readings of texts on various subjects and which covered the interpretation of contents and problematics that allowed students to have a critical posture by means of knowledge related, principally, to the teaching and learning of Geography. The research is being conducted at the Centre for Promotion of Digital and Social Inclusion School (CPIDES), in the multi-functional resource room. The CPIDES was founded on April 8, 2010 and is located in the Faculty of Science and Technology (FCT), Paulista State University (UNESP) "Júlio de Mesquita Filho", campus de Presidente Prudente.
\end{abstract}

Keywords: Audio-Description, Multifunctional Room, CPIDES, TIC 
INTRODUÇÃO

A pesquisa está sendo realizada no Centro de Promoção para Inclusão Digital Escolar e Social (CPIDES), na sala de recursos multifuncionais, localizada na FCT-UNESP de Presidente Prudente $^{1}$. Em nosso caso, iremos descrever as práticas de ensino voltadas a um educando com Deficiência Visual Total realizadas no CPIDES. A metodologia de trabalho utilizada com o educando, foram atividades teóricas e práticas, como vídeos de audiodescrição; leituras tátil do alfabeto Braile, com o objetivo de relembra-lo; foram ministradas leituras de textos sobre temas variados e que abarcassem a interpretação de conteúdos e problemáticas que possibilitam ao estudante possuir uma postura crítica com conhecimentos de assuntos relacionados, principalmente, ao ensino-aprendizagem de Geografia.

O presente artigo tem como objetivo discutir a utilização das Tecnologias da Informação e Comunicação (TIC) para auxiliar o educando nos seus estudos. Uma delas é a audiodescrição, que surgiu nos Estados Unidos em 1975, e no Brasil teve seu início no final dos anos 1990, consagrando-se a partir de 2003, no Festival Internacional de Cinema "Assim Vivemos"2. Em julho de 2011, passou a ser obrigatória nas emissoras de televisão brasileiras com transmissão digital (FRANCO; SILVA, 2010).

Como resultado preliminar, podemos citar os avanços que o mesmo apresentou na escrita Braile, pois tinha esquecido algumas palavras do alfabeto Braile e em pouco tempo ele voltou a dominar de forma progressiva e deu continuidade às leituras até mesmo em sua própria casa como lição diária juntamente com a ajuda de sua família. Outra conquista foi o fato de conseguirmos auxiliar o educando a ter melhores relações interpessoais, visto que isto é essencial em todo trabalho desta natureza.

\section{A TECNOLOGIA ASSISTIVA DE AUDIODESCRIÇÃO}

A Tecnologia Assistiva ${ }^{3}$ de audiodescrição consiste na transformação de imagens em palavras para que informações-chave transmitidas visualmente não passem despercebidas e possam também ser acessadas por pessoas com Deficiência Visual total, parcial ou com baixa visão. O recurso, cujo objetivo é tornar os mais variados tipos de materiais audiovisuais (peças de

\footnotetext{
${ }^{1}$ Pesquisa em andamento.

2 "Assim Vivemos": "O Festival Assim Vivemos" - Festival Internacional de Filmes sobre Deficiência é um festival de cinema temático que exibe filmes que apresentam questões relativas às deficiências de um modo geral. Trata-se do primeiro festival de cinema no Brasil a reunir e apresentar ao público um panorama atualizado e completo do que se produz no mundo sobre este tema. Por ser um festival internacional, os filmes são estrangeiros em sua maioria, falados nas mais diversas línguas". (COSTA, 2010, p. 83).

${ }^{3}$ A respeito da Tecnologia Assistiva, no Brasil, o Comitê de Ajudas Técnicas - CAT, instituído pela PORTARIA N 142 , DE 16 DE NOVEMBRO DE 2006 propõe o seguinte conceito para a tecnologia assistiva: "Tecnologia Assistiva é uma área do conhecimento, de característica interdisciplinar, que engloba produtos, recursos, metodologias, estratégias, práticas e serviços que objetivam promover a funcionalidade, relacionada à atividade e participação de pessoas com deficiência, incapacidades ou mobilidade reduzida, visando sua autonomia, independência, qualidade de vida e inclusão social". (BRASIL, 2014, não paginado).
} 
teatro, filmes, programas de TV, espetáculos de dança, etc.) acessíveis a pessoas com deficiência visual, conta com pouco mais de trinta anos de existência. Entendemos que no caso do Brasil o assunto ainda é muito recente, e assim, a audiodescrição esta começando a dar seus primeiros passos. Utilizamos esta ferramenta para ajudar o estudante com DV a construir seu conhecimento e ter acesso aos conteúdos visuais, pois se trata da tradução em palavras de toda informação visual relevante para a compreensão de uma determinada mensagem (FRANCO; SILVA, 2010).

Compreendemos que a audiodescrição é uma necessidade básica aos Deficientes Visuais, enquanto uma acessibilidade igualitária a todo esse público. O Brasil dá seus primeiros passos. A Bahia é o segundo estado brasileiro com o maior número de deficientes visuais, sendo assim, os educadores buscam audiodescrição como tecnologia assistiva para com os deficientes visuais. O que evidencia uma motivação e um avanço para todos nós lutadores dessa causa em nosso país (SANT'ANNA, 2010; VILARONGA, 2010).

Infelizmente, esse serviço no Brasil ainda é privilégio de poucos. Somente nos grandes centros é possível encontrar eventos audiodescritos, bem como, ainda é irrisória a quantidade de produtos disponíveis no mercado nacional com este recurso. Enquanto a audiodescrição não estiver presente nos principais meios de comunicação de massa, como novelas, filmes, dentre outros, será muito difícil encontrar respostas aos tantos questionamentos formulados nos últimos anos, e que são imprescindíveis para o seu desenvolvimento, tanto em nível técnico quanto prático. Somente com a popularização desta tecnologia assistiva é que será possível formar uma massa crítica que reflita mais claramente as expectativas de todos aqueles que desejam que a audiodescrição realmente cumpra seu papel de informar e incluir a todos que dela necessitam. (SANT'ANNA, 2010, p. 155)

Observamos que, juntamente com a audiodescrição, se faz necessário intercalar todas as informações contidas a partir daquilo que o DV já possui construído, por meio de seu mundo vivido, e também conforme sua alfabetização. Fazemos, então, essa junção com alguns aspectos relevantes no ensino-aprendizagem da geografia e como objeto desse estudo elencamos a categoria de espaço. Sendo assim, segundo Callai e Callai (2003, p.69), nos explica qual é a verdadeira natureza do espaço, dinâmica, e não estática, como já foi concebida na geografia tradicional:

Os homens vivem num espaço, atuam-se nele, ocupam lugares. Esse espaço comumente é visto como algo estático, pronto e acabado. Tem uma aparência. Mas é resultado de uma dinâmica, é cheio de historicidade. A aparência é o resultado, num determinado momento, de coisas que acontecem. É a expressão de um processo, portanto há dinâmica no arranjo. Só na aparência ele é estático, pois este está constantemente sendo construído. E, conhecer o espaço, entendê-lo, é observar esta dinâmica e percebê-lo como resultado, mais de que aceitá-lo como definitivo e acabado. 
Em sendo estático, caberia apenas adaptar-se a ele, ajustar-se para poder viver. E esta era a premissa dos estudos sociais - ajustar ao meio em que vive.

Entendemos que a necessidade de se comunicar é um direito básico voltado ao ser humano, e assim pode se dar de diversas maneiras, seja pela forma oral, por gestos, ou pela audiodescrição. Com a audiodescrição, entramos na linguagem da representação do mundo para com o deficiente visual, que começa a moldar e formatar suas palavras. Podemos compreender o quanto é necessária à junção da realidade do espaço vivido do educando com a comunicação que a audiodescrição Ihe proporciona. Se tornando, sua ferramenta de comunicação a partir de seu olhar de mundo no espaço, na qual, habita. Tendo em vista que olhar o mundo, não é apenas enxerga-lo, pois cada indivíduo tem uma visão sobre o mundo a partir da ideologia que acredita. Como afirma Fantin apud Sant'Anna (2010, p.157):

No entanto, olhar o mundo não envolve só a visão, pois o olhar é fruto de uma individualidade que é parte de uma história pessoal e única vivida em determinada sociedade, com determinada cultura, numa determinada época, vinculada a determinado momento específico de vida, que constroem um jeito próprio de ver. Esse repertório individual envolve, além dos conhecimentos específicos, os valores estéticos, filosóficos, éticos e políticos, assim como a ideologia do indivíduo, do grupo ou da classe social à qual pertence. E nesse processo de educação do olhar, aprendemos a olhar o mundo, a natureza, o trabalho e a arte com o olhar do outro, pela mediação de outros jeitos de olhar. Esses olhares podem ser desinteressados, interpretativos ou criativos.

\section{OS PORTADORES DE DEFICIÊNCIA VISUAL}

Os portadores de Deficiência Visual se dividem em grupos: Cegos e portadores de deficiência visual subnormal. Neste artigo, foi adotada a definição sugerida pela American Foundation for the Blind, para qual criança cega é aquela...

[...] cuja perda de visão indica que pode e deve funcionar em seu programa educacional, principalmente através do uso do sistema Braille, de aparelhos de áudio e de equipamento especial, necessário para que alcance seu objetivos educacionais com eficácia, sem o uso da visão residual. Portadora de visão subnormal, a que conserva visão limitada, porém útil na aquisição da educação, mas cuja deficiência visual, depois de tratamento necessário, ou correção, ou ambos, reduz o progresso escolar em extensão tal que necessita de recursos educativos. (apud MASSINI,1994, p.40).

A causa da Deficiência Visual pode ser hereditária ou adquirida. Enquanto a hereditária é de nascença, a adquirida é contraída logo após o nascimento, principalmente depois que a criança já construiu em seu mundo vivido os conceitos sobre visão, visto que os acidentes são as causas 
mais comuns nesse caso. Podendo assim, a família prestar todo cuidado necessário a criança. Nos casos hereditários, pode acontecer pelo fato da própria mãe e família se descuidar, principalmente do pré-natal, que para a saúde da mãe, é extremamente delicado e importante. Assim, a Deficiência Visual, pode advir da falta de exames pré-natais, acompanhamento médico e vacinas em gerais, bem como, pode ser consequência de erros genéticos. Também, o sarampo, tracoma, oncocercose, glaucoma congênito, catarata e a retinopatia de prematuridade, retinoblastoma, traumas, diabetes, retinose pigmentar são algumas doenças que podem afetar e levar a cegueira. Logo, na percepção de quaisquer alterações é necessário a mãe procurar um médico especialista para tratar e tomar as devidas providências, estas podem amenizar ou mesmo interromper o processo que desencadearia em uma Deficiência Visual (MOSQUERA, 2010).

\section{O CENTRO DE PROMOÇÃO PARA INCLUSÃO DIGITAL, ESCOLAR E SOCIAL - CPIDES: ESTUDO DE CASO DA SALA MULTIFUNCIONAL}

Foi criado em 2010, o “Centro de Promoção para Inclusão Digital, Escolar e Social” (CPIDES) na Universidade Estadual Paulista "Júlio de Mesquita Filho" campus de Presidente Prudente/SP por meio do Grupo de Pesquisa "Ambientes Potencializadores para Inclusão" (API). No CPIDES são realizados atendimentos similares ao Atendimento Educacional Especializado (AEE) como complemento ou suplemento de atividades escolares e nestes utilizam-se recursos pedagógicos acessíveis. As atividades realizadas são direcionadas de acordo com a patologia e interesses do estudante, pois o grupo de estagiários (estudantes de graduação) atende à diversas deficiências. E nesse caso trabalhamos com o Educando T, de 28 anos que possui a Deficiência Visual Total.

Antes de iniciar os atendimentos realizamos entrevistas estruturadas junto aos responsáveis pelos respectivos estudantes para levantamento de informações norteadoras para a elaboração do plano de atendimentos. Os dados coletados e a vivência com os estudantes norteiam a elaboração dos atendimentos, que visam desenvolver suas habilidades e minimizar suas dificuldades. A partir disso levantamos também materiais relacionados aos conteúdos escolares que seriam trabalhados para realização dos atendimentos, o API conta com recursos de Tecnologia Assistiva (TA). Os atendimentos geralmente são realizados na Sala de Recursos Multifuncionais (SRM) e no laboratório de informática do CPIDES (BRUCHMAM; SCHLÜNZEN, 2010). 


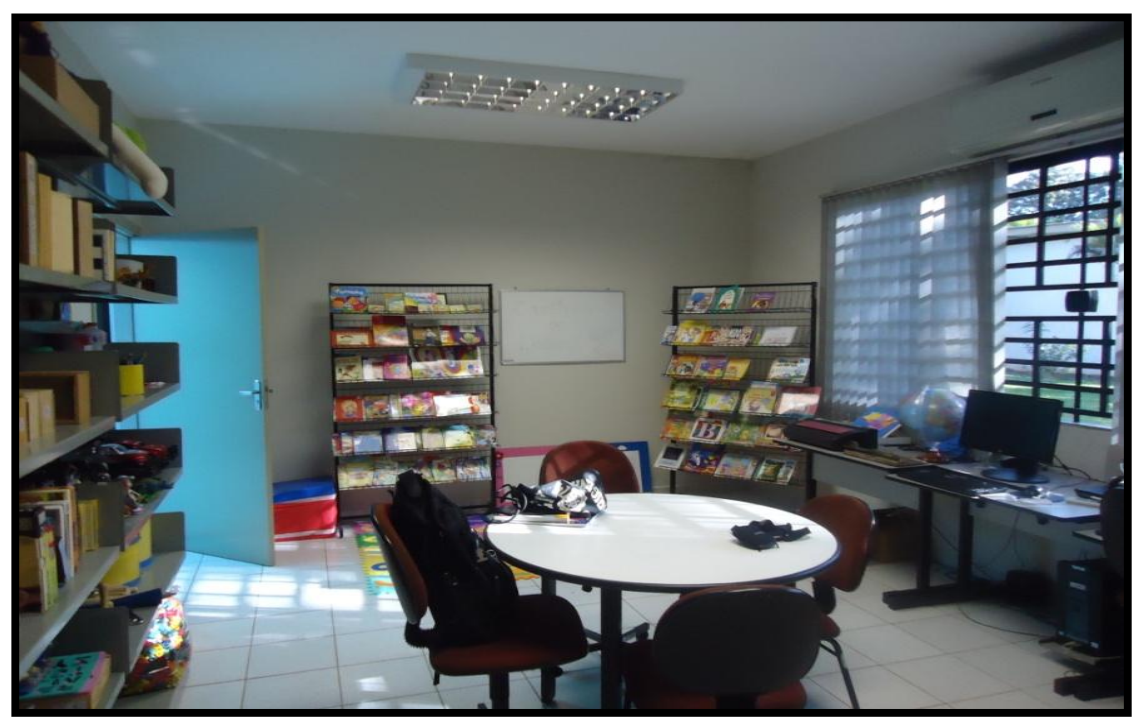

Figura 1. Sala de Recursos Multifuncionais.

Fonte: Autora (2013).

O Educando com Deficiência Visual, antes de iniciar seu primeiro contato com o processo de ensino-aprendizagem, necessita estar incluído em seu novo ambiente, e para isso, é preciso que ele seja conhecedor das particularidades que este ambiente traz, analisando e observando de forma tátil os aspectos dessa paisagem, pois quando encontramos um ambiente inacessível, fica difícil não somente para o educando se deslocar, mas impossibilita a prática de novas técnicas de ensino-aprendizagem que possam auxiliar, também, em suas interações com o restante da sociedade e para com o mesmo (MOSQUERA, 2010).

Em síntese, em nosso trabalho com o educando, foram realizadas leituras tateáveis do alfabeto Braile, com o objetivo de relembrar o alfabeto. Foram ministradas leituras de textos sobre temas variados e que abarcassem a interpretação de conteúdos e problemáticas que possibilitam ao educando construir uma postura crítica com conhecimento de assuntos relacionados, principalmente, ao ensino-aprendizagem de Geografia. Também, foram realizadas atividades como jogos lúdicos, brincadeiras e desafios que motivaram o educando $\mathrm{T}$, a tatear maquetes com relevos e, também, o Globo que possui o Mapa Mundial o que permitiu ao educando identificar os países ali existentes e ter uma melhor compreensão da localização dos países, os respectivos oceanos e linhas dos Trópicos ali presentes. O trabalho foi efetuado com o intuito inicial de levar o conhecimento ao educando T. Como resultado preliminar, podemos citar os avanços que apresentou na escrita Braile, pois tinha esquecido algumas palavras do alfabeto Braile e em pouco tempo ele voltou a dominar de forma progressiva e deu continuidade às leituras até mesmo em sua própria casa como lição diária, juntamente, com a ajuda de sua família. 
Conseguimos, também, auxiliar o estudante a ter melhores relações interpessoais, visto que é essencial em todo trabalho desta natureza.

\section{CONSIDERAÇÕES FINAIS}

Nosso estudo de caso teve como seu principal objetivo entender a inclusão do educando T, conforme foi apresentada sua patologia, a Deficiência Visual. A experiência nos remete a pensar que todos nós videntes e deficientes visuais somos dotados de inúmeras dificuldades e, também, de imensas qualidades, visto que essas qualidades devem ser exploradas, qualificadas e acima de tudo potencializadas tornando o aprendizado para o educando, algo adquirido, interessante e significativo.

$\mathrm{O}$ educando $\mathrm{T}$, demonstrou muito interesse em todo processo de ensino-aprendizagem voltado ao ensino de geografia o que pode facilitar nosso trabalho que desde o início teve o intuito de prepará-lo ao possível vestibular, conforme assim o educando demonstrou o interesse desde o começo. Os recursos voltados à tecnologia assistiva como a audiodescrição fez com que o educando pudesse relembrar e aprofundar melhor sua escrita e diálogo, tendo por assim uma melhora em suas posturas interpessoais. Além de ter sido atribuído ao educando diversos conteúdos ligados ao ensino aprendizagem de geografia, o mesmo apresentou inúmeras dúvidas e discussões significativas e produtivas para seu processo de conhecimento;

É importante, também, deixarmos claro que aqui compartilhamos autores que tem diversos interesses comuns, todos ligados a Deficiência Visual, suas dificuldades, necessidades e voltados à inclusão, além dos que falam do ensino de Geografia.

Portanto, todas as atividades aqui realizadas foram apenas resultados de um início de processo de ensino-aprendizagem mediada por todos nós estagiários e voluntários do CPIDES que, muitas vezes, obtivemos avanços, uma vez que através da realização de atividades contextualizadas conseguimos despertar o interesse e a curiosidade de cada estudante buscando a construção do conhecimento.

\section{REFERÊNCIAS}

BRASIL. Decreto no. 3.298, de 20 de dezembro de 1999. Disponível em: <http://www.cedipod.org.br>. Acesso em: 30 mar. 2014.

BRASIL. Tecnologia assistiva. ATA VII. Comitê de Ajudas Técnicas (CAT). Coordenadoria Nacional para Integração da Pessoa Portadora de Deficiência (CORDE). Secretaria Especial dos Direitos Humanos. Disponível em: <http://www.assistiva.com.brtassistiva.html>. Acesso em: 29 jun. 2014. 
BRUCHMAM, C. S.; SCHLÜNZEN, E. T. M. Tecnologias de informação e comunicação como ferramentas potencializadoras na abordagem e valorização da ética na educação inclusiva. Colloquium Humanarum, v. 07, p. 751-755, 2010.

CALLAI, Helena Copetti; CALLAI, Jaeme Luiz. Grupo, espaço e tempo nas séries iniciais. In: CASTROGIOVANNI, Antonio Carlos et al. (Orgs.). Geografia em sala de aula: práticas e reflexões. 4. ed. Porto Alegre: UFRGS; Porto Alegre: AGB - seção Porto Alegre, 2003. p. 65-75.

CHAVES, Ana Paula Nunes. Ensino de geografia e a cegueira: diagnóstico da inclusão escolar na grande Florianópolis. 2010. 159 f. Dissertação (Mestrado em Geografia) - Centro de Filosofia e Ciências Humanas, Universidade Federal de Santa Catarina, Florianópolis.

COSTA, Graciela Pozzobon, Audiodescrição e Voice Over no festival assim vivemos. In: MOTTA, Lívia Maria Villela de Mello, FILHO, Paulo Romeu (Orgs.). Audiodescrição: transformando imagens em palavras. São Paulo: Secretaria dos Direitos da Pessoa com Deficiência do Estado de São Paulo, 2010.p. 83-92.

FRANCO, Eliana Paes Cardoso; SILVA, Emanuela Cristina Correa Carvalho da. Audiodescrição: breve passeio histórico. In: MOTTA, Lívia Maria Villela de Mello, FILHO, Paulo Romeu (Orgs.). Audiodescrição: transformando imagens em palavras. São Paulo: Secretaria dos Direitos da Pessoa com Deficiência do Estado de São Paulo, 2010. p. 23-42.

MASSINI, E. F. S. A educação do portador de deficiência visual: as perspectivas do vidente e do não vidente, Brasília, ano 13, n.60, out./dez. 1993.

MOSQUERA, C. F. F. Deficiência visual na escola inclusiva. Curitiba: Ibipex, 2010.

NUNES, E. V.; MACHADO, F.O; VANZIN, T. Ambiente virtual de aprendizagem inclusivo. Florianópolis: Pandion, 2011.

SANT'ANNA, Laércio. A Importância da audiodescrição na comunicação das pessoas com deficiência. In: MOTTA, Lívia Maria Villela de Mello; FILHO, Paulo Romeu (Orgs.). Audiodescrição: transformando imagens em palavras. São Paulo: Secretaria dos Direitos da Pessoa com Deficiência do Estado de São Paulo, 2010. p. 151-158.

SCHLÜNZEN, Elisa Tomoe Moriya. Considerações finais e perspectivas futuras. In:

Mudanças nas práticas pedagógicas do professor: criando um ambiente construcionista, contextualizado e significativo para crianças com necessidades especiais físicas. 2000. $252 \mathrm{f}$. Tese (Doutorado em Educação) - Pontifícia Universidade Católica de São Paulo - PUC, São Paulo. p. 220239.

VILARONGA, Iracema; Olhares cegos: a audiodescrição e a formação de pessoas com deficiência visual. In: MOTTA, Lívia Maria Villela de Mello, FILHO, Paulo Romeu (Orgs.). Audiodescrição: transformando imagens em palavras. São Paulo: Secretaria dos Direitos da Pessoa com Deficiência do Estado de São Paulo, 2010.p.159-166. 